\title{
Global Accent in the Portuguese Speech of Heritage Returnees
}

\author{
Cristina Flores \\ University of Minho \\ Anabela Rato \\ University of Toronto
}

\begin{abstract}
The present study examined whether heritage speakers (HSs) of European Portuguese (EP) who were born or moved to a German-speaking country before the age of eight years were perceived as native speakers of EP. In particular, this study intended to determine whether a change of linguistic environment, length of residence in a migrant context, length of residence in the country of origin before migration and after remigration, and age at return could predict the degree of (non)native accent in the heritage language. Thirty native Portuguese speakers assessed the global accent of 20 Portuguese-German bilinguals, five Portuguese monolinguals and five highly proficient German speakers of Portuguese as a second language (L2). The group of HSs comprised 17 speakers who returned to Portugal. The results revealed that listeners perceived a strong global foreign accent in the speech of the L2 learners, while the monolingual Portuguese speakers were clearly perceived as being native speakers of EP. The HSs' ratings were considerably closer to the monolingual average ratings, but they showed more variation, indicating that their accent may bear non-native traces. Further analyses showed that the age at which the HSs emigrated was the only significant predictor, while length of residence in the host country and in Portugal were less predictive.
\end{abstract}

Keywords: heritage language, returnees, global accent, European Portuguese

\section{INTRODUCTION}

The study reported in this paper aims at investigating whether global accent is affected by input alterations across the lifespan, focusing on adult heritage speakers (HSs) of European Portuguese (EP) who grew up and either still live in Germany or have returned to their country of origin, Portugal. In particular, this study examined whether the accent of the HSs who return to the country of origin (henceforth, returnees) is perceived as being more native-like than the accent of those who live in the country to which they migrated.

HSs are early bilinguals with a background of family migration who grow up being exposed to two languages on a daily basis. The language spoken at home (and within the immigrant community, if HSs socialize with people who have a similar background), or the so-called heritage language (HL), is generally the first language (L1) to which HSs are exposed. Exposure to the societal language may start at birth, if it is frequently spoken within the family, or it could increase steadily as these children start to socialize outside home and go to kindergarten/school (Montrul, 2010; Rothman, 2009). In cases in which children immigrate early in life, the HL is clearly the L1 and the societal language is the second language (L2) acquired. Thus, HSs are either simultaneous or early successive bilinguals. What is important to highlight here is that in any of these circumstances, the HL is typically the L1 to which HSs are exposed to as children 
(or one of two L1s, i.e., 2L1). Cases in which speakers with backgrounds of migration do not have any contact with the family language in childhood, and instead begin acquiring this language later in life, are clearly cases of L2 acquisition and should not be subsumed under the label of HL development (Flores, 2015).

Keeping in mind these particularities, the variables age of onset of language acquisition (AOA), quality of exposure, quantity of exposure and length of residence (LOR), which can be crucial predictors of L2 acquisition and, in particular, L2 pronunciation (Piske, MacKay, \& Flege, 2001), have to be addressed differently in HL and L2 research. Since AOA refers to the onset of acquisition of the L2 (and not the HL, which is acquired from birth), it may affect the development of a HL in the sense that from this point onward, the HL is no longer the only language in a speaker's mind, but has to compete with another one (see the discussion in Montrul, 2008). This process interacts with the variables quality of input and quantity of input. When a HL child starts to be exposed to the societal language (e.g., through schooling), contact with the HL becomes more reduced and is often restricted to communication within the family, a situation that lasts until adulthood. Cases in which HSs lose complete contact with their HL are less frequently documented (e.g., Au, Knightly, Jun, \& Oh, 2002). Additionally, HSs tend to be primarily exposed to colloquial registers of the HL, and thus, have reduced contact with more formal registers provided by schooling (Rinke \& Flores, 2014). Furthermore, it may be the case that the input provided by the adult migrant community has undergone changes that distinguish it from the homeland variety (Silva-Corvalán, 1994, for Spanish in the U.S.; Nagy \& Kochetov, 2013, for Russian in Canada). Whether one or the combination of all these variables leads to the development of accented speech in the HL constitutes our first research question.

The vast number of studies focusing on the development of phonological competence in migrants has analyzed speakers' L2 (e.g., Flege, Munro, \& MacKay, 1995; Flege, Frieda, \& Nozawa, 1997; Flege, Yeni-Komshian, \& Liu, 1999; Thompson, 1991), or the dominant societal language. Research on migrants' L1 (or on both of their languages) is much scarcer, but the results we have so far indicate that exposure to a language since birth may not be a guarantee per se for the development and/or maintenance of native-like pronunciation, even when speakers maintain contact with the L1 well into adulthood (De Leeuw, Schmid, \& Mennen, 2010; Godson, 2004; Kupisch, Barton, Klaschik, Lein, Stangen, \& van de Weijer, 2014; Lein, Kupisch, \& van de Weijer, 2015; Stangen, Kupisch, Proietti Erguen, \& Zielke, 2015; Vago, 1991). In the case of second or third-generation migrants, the strong presence of the societal language from early on may lead to contact-induced changes in the HL sound system and, consequently, to the development of accented pronunciation, despite early exposure (Godson, 2004; Kupisch, Barton, Klaschik, Lein, Stangen, \& van de Weijer, 2014; Stangen, Kupisch, Proietti Erguen, \& Zielke, 2015). Studies on L1 attrition have shown that these changes may even occur when immersion in a new linguistic environment takes place in adulthood and lasts over decades (De Leeuw, Schmid, \& Mennen, 2010; Hopp \& Schmid, 2013). These findings indicate that the effects of the dominant language may extend over a lifetime, leading us to our second research question: What happens to HSs' pronunciation if they grow up in an environment where their HL is a minority language, but then moved to the homeland, where the once minority language is the societal language? 


\section{Research on the Development of L1 Pronunciation in a Migrant Context}

Although there is much research on L1 child and L2 adult speech acquisition, the phonological/ phonetic competence of HSs has not been as widely investigated. This group of speakers is of particular interest due to the linguistic specificities underlying the acquisition of the HLs in a migrant context. These specificities arise from the fact that, even though HSs tend to be exposed to their HL from birth, early exposure is constrained by reduced contact with this language and the strong presence of a societally dominant language.

Due to early language exposure, a typical HS is predicted to have better linguistic competence than an L2 adult learner (Campbell \& Rosenthal, 2000), especially at the phonological level and in grammatical domains that are acquired early in native language development (Benmamoun, Montrul, \& Polinsky, 2013; Montrul, 2015). Previous studies examining the phonological competence of HSs have found that exposure to a minority language in early childhood improves both production and perception of that language in adulthood in comparison to L2 learners, even in cases of prolonged loss of contact with the HL (e.g., Flores \& Rauber, 2011; Knightly, Jun, Oh, \& Au, 2003; Oh, Jun, Knightly, \& Au, 2003).

The phonological competence of HSs has been investigated by using global accent ratings, acoustic measures (e.g., voice onset time (VOT)), and perceptual measures (e.g., accurate identification/discrimination of phonemes). Globally, these studies have shown that HSs' phonological competence tends to be a well-preserved aspect of linguistic knowledge in HL development, although certain phonetic elements in the speech of HSs may diverge from the native form (Chang, Yao, Haynes, \& Rhodes, 2011; Godson, 2004; Hrycyna, Lapinskaya, Kochetov, \& Nagy, 2011; Kim, 2012; Lukyanchenko \& Gor, 2011; Nagy \& Kochetov, 2013; Rao, 2015; Rao \& Ronquest, 2015; Ronquest, 2013; Rato, Flores, Neves, \& Oliveira, 2015).

A few studies have addressed the question of whether phonetic segments and suprasegmentals are perceived as a foreign accent in native speech (Kupisch, Barton, Klaschik, Lein, Stangen, \& van de Weijer, 2014; Kupisch, Lein, Barton, Schröder, Stangen, \& Stoehr, 2014; Rato, Flores, Neves, \& Oliveira, 2015; Stangen, Kupisch, Proietti Erguen, \& Zielke, 2015). Rato, Flores, Neves and Oliveira (2015) investigated the phonological competence of HSs of EP who were born and lived in Germany. The Portuguese speech of 12 heritage bilinguals was assessed in terms of global foreign accent, comprehensibility and intelligibility by native Portuguese raters, and compared to the oral production of a group of six monolingual Portuguese speakers and a group of six proficient learners of L2 Portuguese who were German. The global accent rating task followed the procedure of De Leeuw, Schmid and Mennen (2010), who used a two-step task. First, binary judgment raters labeled samples as native or non-native speech. This choice was followed by an indication of degree of certainty on a three-point scale. The results showed that ten bilinguals were globally perceived as native speakers of EP, which seems to indicate that early exposure to the HL can be a strong predictor of global native accent development. However, there was more variation in their ratings than in the control groups', particularly because there were two HSs whose ratings showed less consistency and lower degrees of certainty of native accent. Comprehensibility and intelligibility ratings yielded similar results for bilingual and monolingual speakers; that is, the speech of HSs was evaluated as being easily understood and intelligible. 
However, other studies show that HSs are not always rated as having a native-like accent in their HL. Kupisch Lein, Barton, Schröder, Stangen and Stoehr (2014) compared the linguistic performance of two groups of German-French bilinguals whose HL was French. One group was born in France but moved to Germany during childhood, and the other group grew up in France but moved to Germany during adulthood. The authors examined their performance in different domains, including morpho-syntax and phonetics, and concluded that both groups of HSs performed quite native-like in all domains except for pronunciation. The ratings of global foreign accent showed that the HSs of French, who spent their childhood in Germany, were judged as native-like significantly less often than the group of bilinguals with French as their stronger language (i.e., who moved to Germany as adults). The overall production of VOT did not differ significantly between groups; however, the HSs differed significantly from monolinguals in the production of VOT for coronal and dorsal plosives.

In a subsequent study, Kupisch, Barton, Klaschik, Lein, Stangen and van de Weijer (2014) investigated the competence of adult French-German and Italian-German simultaneous bilinguals in the domain of phonetics through an assessment of global foreign accent both in their HLs (i.e., French and Italian) and their majority language (i.e., German). The findings revealed that the HSs' majority language was produced with no foreign accent, while the pronunciation of their HLs showed more variation, falling between the ratings of L1 and L2 learners. The HSs of French and Italian investigated by this study team differ from those of Rato, Flores, Neves and Oliveira (2015) with respect to the HL input they were exposed to in their early years. While the French and Italian HSs were raised in mixed families in which two languages (i.e., majority and heritage) were spoken daily, the Portuguese HSs were all raised in first-generation migrant families in which Portuguese was the dominant home language.

Stangen, Kupisch, Proietti Erguen and Zielke (2015) investigated the effect of age of onset of acquisition and whether HSs acquire a native accent in both languages by comparing two groups: simultaneous Turkish-German bilinguals with an AOA of German and Turkish before the age of three, and early L2 learners with an AOA in German after the age of four. HSs' speech samples were rated by native speakers of each language. The results showed that exposure from birth to Turkish and early exposure to German did not ensure native-like speech in both languages; however an AOA effect was found in the speakers with an AOA of German after age four. These speakers were more often considered native-like only in their HL and not in the majority language; thus, the attainment of native pronunciation in both languages seems less likely in these types of cases.

Many studies have used global foreign accent ratings to assess the phonological competence of HSs, but there are also a large number of studies that have used acoustic measures instead. One example is the study by Chang, Yao, Haynes, and Rhodes (2011), who investigated the speech of HSs of Mandarin living in an English-speaking country by acoustically analyzing the first (F1), second (F2) and third (F3) formants of vowels, the VOT of word-initial plosives, and the peak amplitude frequency (PAF) and centroid frequency of fricatives. The study, which compared the phonetic performance of HSs to that of L2 learners of Mandarin, revealed that, overall, HSs were the most successful at maintaining phonological contrasts in their HL (i.e., Mandarin), thus 
showing a near-native ability. However, despite their overall ability to perceive and produce phonological contrasts in their HL, the results implied that they may be perceived as non-native speakers due to cross-linguistic influence from the dominant language, particularly in the production of phonetic contrasts that are in both their languages.

Although HSs are able to perceive and produce phonetic contrasts of their HL, they may show a slight foreign accent in their speech due to cross-linguistic influence from the dominant language regarding, specifically, contrasts that are similar (but not identical) in both of their languages. This is shown by Godson (2004), who found such cross-language influence in the speech of HSs of Western Armenian. The production of Armenian vowels that were more similar to those of English (i.e., the dominant language) showed cross-linguistic influence, especially in the case of speakers who immigrated to the U.S. during their childhood (i.e., interrupted acquirers). However, the influence of the dominant language did not fully neutralize similar vowel contrasts, and as such, HSs maintained separation of Armenian and English vowels.

Hrycyna, Lapinskaya, Kochetov and Nagy (2011) investigated VOT of onset voiceless stops /p, $\mathrm{t}, \mathrm{k} / \mathrm{in}$ the conversational speech of three generations of speakers of three HLs (i.e., Russian, Ukrainian, Italian) living in Toronto, Canada. The results showed that the VOT of HSs tended to drift from the minority language's standard VOT values toward that of the dominant language (i.e., English) in successive generations. Nagy and Kochetov (2013) investigated the same acoustic measure further with larger groups, representing three to five generations of speakers in each HL, and also found that across generations, the VOT of HSs of Russian and Ukrainian drifted away from the standard short-lag (of all three minority languages examined) and toward the long-lag of English. However, for Italian, the cross-generational change from short- to longlag was in the opposite direction. One of the possible explanations put forth by the authors for the maintenance of Italian VOT standards/values was the reported amount of Italian input that third-generation speakers were exposed to both in the classroom (due to institutional support for Italian in Toronto) and at home.

The studies carried out by Kim (2012), Lukyanchenko and Gor (2011), Ronquest (2013), and Rao (2015) confirm the main picture that arises from research on HL phonology. Early exposure to the HL fosters the development of an accent that is similar, but not identical to that of monolingual peers. Factors related to amount of language use (of both the HL and the societal language), L1 and L2 proficiency, AOA of the societal language, and environmental changes influenced HSs' pronunciation in a way that it demonstrated properties not found in monolinguals' accent, leading to a heritage accent, as proposed by Rao (2015, p. 66). Variation among these factors was also the source of the high levels of individual variation found in most of these studies on HL phonology.

Additionally, some studies have also shown that the phonological performance of adult speakers can change in an L2 migrant setting. For example, De Leeuw, Schmid and Mennen (2010) investigated whether native speakers of German living either in Canada or the Netherlands were perceived to have a foreign accent in their native German speech. The consecutive GermanEnglish and German-Dutch bilinguals had moved to the host countries at an average age of 27 years and had lived there for an average of 37 years. The results showed that the German raters 
perceived a global foreign accent in the German speech of both groups of consecutive bilinguals and that nine immigrants to Canada and five immigrants to the Netherlands were perceived as non-native speakers of German. These findings seem to suggest that when acquiring an L2 in adulthood, phonological competence of a native language may be influenced by a dominant language after long-term residence in a migrant setting.

Hopp and Schmid (2013) investigated the role of AOA and cross-linguistic influence in L2 acquisition in a group of post-puberty German emigrants to Anglophone Canada and the Netherlands. The phonological competence of this group, who emigrated after the age of 17 and spent a period of immersion of more than 15 years in a migrant context, was compared to two other groups: a group of Dutch and English late advanced learners of L2 German, and a group of native speakers of German living in Germany. The authors concluded that language acquisition from birth is not sufficient to develop a native-like accent in bilingual speech. However, although the German emigrants' accent was perceived as bearing traces of non-native speech, such judgments did not occur to the same degree as they did with the advanced L2 learners' accent.

The present study aims to contribute to the ongoing research on HL phonology by focusing on an understudied HL (i.e., EP) and on a particular case of environmental change; that is, the return of HSs to their country of origin.

\section{The PRESEnT StUdy}

\section{Speakers and Predictor Variables}

Speech samples from three groups of adult speakers of EP -- (i) HSs, (ii) learners of L2 EP, and (iii) native/monolingual EP speakers -- were rated by 30 EP listeners based on their degree of perceived global native accent. The experimental group comprised 20 HSs of EP who were raised bilingually in Germany or in the German-speaking part of Switzerland (mean age $=23.6$ yrs, $\mathrm{SD}=4.2$ ).

Additionally, two control groups were included. The monolingual control group included data from five native speakers of EP who lived in Portugal and had never lived abroad for more than three months (mean age $=32.2 \mathrm{yrs}, \mathrm{SD}=8.6$ ). They spoke only EP during their childhood and started to learn English as a foreign language at school. None of these five participants knew (or had learned) German. Speech samples from this group were collected from the sociolinguistic corpus Sociolinguistic Profile of Braga speech, built at the University of Minho.

The L2 control group included speech samples from five highly proficient L2 learners of EP whose L1 was German (mean age $=31.0$ yrs, $\mathrm{SD}=7.1$ ). All speakers acquired EP as adults and had a close familial or professional connection to this language, speaking it frequently in their daily lives. Besides frequent visits to Portugal, no speaker had been a long-term resident (i.e., had lived more than three months) in Portugal.

The 20 HSs were second-generation migrants who grew up either in Germany $(n=14)$ or in the German-speaking part of Switzerland $(n=6)$. Background information was gathered through an extensive oral interview, conducted for the research project Portuguese-German Bilingualism in the European Context. All HSs reported to have two first-generation parents ${ }^{1}$ who immigrated in 
the 1970s or early 1980s. During these HSs' childhood and adolescence, EP was the dominant language spoken at home. German was spoken between siblings and cousins, but was rarely used to address parents. In parallel with their official German school, all speakers attended an extracurricular HL course (two hours per week), in which they learned basic literacy skills in their HL. When asked about language preferences and proficiency while living in Germany/Switzerland, all speakers identified German as their preferred and stronger language. Additionally, all participants rated their overall proficiency in German higher than in EP.

The HSs differed with respect to four main variables: age of migration, age of return, LOR in their parents' homeland after returning there (i.e., LOR in Portugal) and length of residence in the German-speaking country (i.e., LOR host country) (see Table 1). Nine of the 20 speakers were born in Germany/Switzerland. The other 11 speakers were between three and six years old when their parents left Portugal (mean $=2.5 \mathrm{yrs}, \mathrm{SD}=2.52$, range $=0$ to $7 \mathrm{yrs}$ ). In the case of speakers who were born in the host country, it was difficult to clearly define when intense exposure to German started, since EP was the language most used at home. Nevertheless, it is not realistic to assume that, even in cases of a strong presence of the HL, the heritage child lived completely isolated from the societal language, which is spoken outside the home, by siblings and other children, and in the media (e.g., TV and radio). We therefore assumed that contact with German began at birth, even though German input was probably much less than exposure to EP during the first years of life. We defined age of migration as a predictor variable since a later age of migration correlates with a longer period of monolingualism in childhood, during which the speaker was only exposed to EP.

As for the variable LOR in Portugal, our HSs group comprised two types of speakers. Three participants lived in Germany at the time of data collection, while the other 17 speakers moved to Portugal after spending childhood/adolescence in a German-speaking country. Although in some cases, the participants were born in Germany/Switzerland, meaning moving to Portugal was not a real "return," but rather a move to their parents' homeland, we will henceforth call both of these speaker types returnees. The LOR "back" in Portugal ranged from five months to 14 years (mean LOR in Portugal $=4.9 \mathrm{yrs}, \mathrm{SD}=4.46$, range $=0$ to $14 \mathrm{yrs}$ ). Returnees were between 11 and 29 years old when they moved to Portugal (mean $=18.5 \mathrm{yrs}, \mathrm{SD}=5.42$, range $=$ 11 to $20 \mathrm{yrs}$, non-returnees were excluded in this case). This means that they lived in the host country (i.e., Germany or Switzerland) for an average of 16 years (SD $=6.42$, range $=6$ to 29 yrs). After moving to Portugal, the returnees either went to school, to a university or, in three cases, started working. When participants were asked about reasons for remigration and the process of integration into Portuguese society after returning, two types of responses were given. The returnees who came to Portugal in adolescence came with their parents and did not have any say in the decision, while the older returnees moved to Portugal willingly in order to study there. Although different experiences of integration into Portuguese society were reported, at the time of data collection, all returnees expressed positive attitudes towards living in Portugal. No one planned to move back to Germany or to Switzerland in the near future.

All the monolingual speakers and the raters were from and lived, at the time of data collection, in northwest Portugal. It is also important to highlight that the parents of the HSs were originally from the same region in Portugal. 
Table 1.

Overview of HS Participants

\begin{tabular}{|c|c|c|c|c|c|}
\hline Speaker & $\begin{array}{l}\text { Age at data } \\
\text { collection }\end{array}$ & $\begin{array}{c}\text { Variable } 1 \\
\text { Age at } \\
\text { Emigration }\end{array}$ & $\begin{array}{c}\text { Variable } 2 \\
\text { LOR in Portugal }\end{array}$ & $\begin{array}{l}\text { Variable } 3 \\
\text { LOR in host } \\
\text { country }\end{array}$ & $\begin{array}{c}\text { Variable } 4 \\
\text { Age at Return }\end{array}$ \\
\hline HS_1 & 28 & 4 & 0.4 & 24 & 28 \\
\hline HS_2 & 22 & 0 & 6 & 16 & 16 \\
\hline HS_3 & 33 & 0 & 14 & 19 & 19 \\
\hline HS_4 & 30 & 5 & 3 & 22 & 27 \\
\hline HS_5 & 23 & 0 & 9 & 14 & 14 \\
\hline HS_6 & 19 & 3 & 7 & 9 & 13 \\
\hline HS_7 & 30 & 0 & 1 & 29 & 29 \\
\hline HS_8 & 26 & 0 & 12 & 14 & 14 \\
\hline HS_9 & 19 & 4 & 9 & 6 & 11 \\
\hline HS_10 & 24 & 0 & 9 & 15 & 15 \\
\hline HS_11 & 22 & 6 & 6 & 10 & 16 \\
\hline HS_12 & 22 & 3 & 0.4 & 19 & 22 \\
\hline HS_13 & 23 & 7 & 3 & 13 & 20 \\
\hline HS_14 & 18 & 3 & 7 & 8 & 15 \\
\hline HS_15 & 24 & 4 & 9 & 11 & 15 \\
\hline HS_16 & 19 & 0 & 0 & 19 & $\mathrm{n} / \mathrm{a}$ \\
\hline HS_17 & 20 & 5 & 0.5 & 9 & 19 \\
\hline HS_18 & 21 & 6 & 0 & 15 & $\mathrm{n} / \mathrm{a}$ \\
\hline HS_19 & 27 & 0 & 0 & 27 & $\mathrm{n} / \mathrm{a}$ \\
\hline HS_20 & 22 & 0 & 1 & 21 & 21 \\
\hline $\begin{array}{l}\text { Mean } \\
\text { (SD) }\end{array}$ & $\begin{array}{l}23.6 \\
(4.2)\end{array}$ & $\begin{array}{c}2.5 \\
(2.5)\end{array}$ & $\begin{array}{c}4.9 \\
(4.5)\end{array}$ & $\begin{array}{c}16 \\
(6.4)\end{array}$ & $\begin{array}{l}18.5 \\
(5.4)\end{array}$ \\
\hline
\end{tabular}

\section{Raters}

The group of raters included 30 native speakers of EP ranging from 18 to 40 years of age (mean age $=22.7 \mathrm{yrs} ; \mathrm{SD}=6.7$ ). They were all born and raised in northwest Portugal and were studying Applied Languages at the University of Minho or already had a degree in Humanities. Apart from two participants, who had very basic knowledge of German (i.e., on the elementary level), no other listener knew German. All raters reported having no hearing impairments.

\section{Materials and Procedure}

The global accent rating process included speech samples collected in three semi-spontaneous production tasks: a biographic interview, an extemporaneous recounting of a story, and picture 
descriptions. The selection of stimuli was based on five criteria: (i)full sentences, (ii)no morphological, lexical or syntactic deviations in these sentences, (iii)no hesitations, (iv)no long pauses (i.e., < 0.3 seconds, s), and (v)no cultural information (i.e., information that could identify the migrant context). Although the speech samples had no lexical or morphosyntactic deviations, bias caused, for example, by range and variability of lexicon and grammatical structures may be found in the listeners' assessments, as acknowledged by De Leew, Schmid and Mennen (2009).

Following the procedure of a previous study (Rato, Flores, Neves, \& Oliveira, 2015), three sentences per speaker were selected, yielding a total of 90 sentences, and these were concatenated into sequences of three speech samples with a 0.99 normalized peak intensity and a two-second inter-stimulus interval (ISI), which gave the raters sufficient segmental and suprasegmental data to assess the samples in terms of degree of nativeness. The sentences produced by the three groups of speakers did not differ significantly in terms of mean duration $(F$ $(2,27)=2.31, p>.05)$, ranging from $3.5 \mathrm{~s}$ to $4.5 \mathrm{~s}$ (mean duration $=4.2 \mathrm{~s} ; \mathrm{SD}=1.21)$. Moreover, no significant intergroup differences were found in the production of intrasentential pauses $(F$ $(2,27)=.71, p>.05)$. The mean duration of intrasentential pauses ranged from $0.11 \mathrm{~s}$ to $0.19 \mathrm{~s}$ (mean duration $=0.17 \mathrm{~s}, \mathrm{SD}=0.13$ ) The 30 triads of sentences (i.e., sequences of 3 sentences $\mathrm{x} 30$ speakers) were presented twice in a randomized order. Example (1) shows a concatenated sequence of three sentences $(\mathrm{a}-\mathrm{c})$ produced by a bilingual speaker.

(1) a. Pela minha experiência simplesmente estamos lá sentados a falar, conversar. Põem-nos umas bolachas e assim. (buzz)

'According to my experience we are sitting there, speaking, talking. Someone serves some cookies and that's it.'

b. É a assistência social também que disponibiliza algumas casas, edifícios, assim, para essas pessoas pelo menos terem um teto sobre a cabeça. (buzz)

'It is the social assistance that also provides some houses, buildings, so that those people have, at least, a roof over their heads.'

c. Pelo menos, também, se vê muitas vezes no telejornal que as pessoas vivem em casas sem condições nenhumas. E pronto, em bairros mesmo de pobreza. (buzz)

'At least, we also watch on the TV news that people live in houses without any living conditions. And, yes, in very poor neighborhoods.'

The global accent task was set up in $T P$, v. 3.1. (Rauber, Rato, Kluge, \& Santos, 2012), which is a software application used for speech perception experiments. It was installed on 30 computers in a quiet computer lab. The task ran simultaneously on the computers and the group of raters performed the task individually with NGS MSX6 Pro stereo headphones. Before the administration of the task, instructions about the procedure were first explained orally and then displayed on each computer screen. Although raters were informed they were going to hear speech samples produced by speakers of Portuguese, no information about the first language(s) 
of the speakers was provided. Moreover, raters were instructed not to base their judgments on regional dialects.

After these brief instructions, the listeners undertook a training task so as to become familiarized with both the task design and procedure and the stimuli. The training task included four triads of stimuli not included in the rating task: a sequence of three sentences produced by a monolingual speaker, one from an L2 speaker with a clearly perceivable foreign accent, and two speech sequences from two HSs. This training allowed the raters to attune their perception by listening to the two endpoints of global (non-) native accent (i.e., unaccented and heavily accented global accent) and therefore establish native and non-native references.

In the global accent rating task, the stimuli were presented aurally and the Portuguese listeners had to rate them according to degree of nativeness on a 9-point Likert scale $(1=$ unaccented, $9=$ heavily accented), following a similar procedure to Munro and Derwing (1994), and YeniKomshian, Flege and Liu (2000). A low foreign accent rating was illustrative of a speaker who was perceived as native or near-native, and a high foreign accent rating was indicative of a speaker who was perceived as having a strong foreign accent in their Portuguese speech samples. A larger scale than the one in Rato, Flores, Neves and Oliveira (2015) was used in order to further examine the heterogeneity reported in the ratings given to group of HSs, and thus allow for finer distinctions regarding degree of global foreign accent.

The average of the two ratings given to the speech samples of each speaker by the Portuguese listeners was calculated and used as the criterion variable. The predictor variables were those shown in Table 1: (i) age of emigration, corresponding to the age the speakers began their immersion in a bilingual environment, (ii) LOR in Portugal, corresponding to the period of time the returnee HSs had spent in Portugal since their return, (iii) LOR in the host country, indicating the time spent in Germany/Switzerland between migration and return (for returnees) or since migration (for HSs living in Germany), (iv) age at return, indicating the age at which the returnee HSs moved to Portugal.

Statistical analyses were performed in SPSS 20.1. Due to the unbalanced number of participants in the different groups (i.e., 20 speakers in the HS group and five speakers in each of the other two groups), non-parametrical tests were applied for the statistical analyses. Kruskal-Wallis and Mann-Whiney tests were run for between-group comparisons. In order to verify whether there was an effect of the four extra-linguistic variables on the HSs' accent ratings, a Pearson Correlation Coefficient test was performed for each variable. Furthermore, in order to examine if there was consistency among the foreign accent ratings provided by the native EP listeners, a two-way consistency average-measures intra-class correlation (ICC) was computed to assess inter-rater reliability (IRR).

\section{Research Hypotheses}

As summarized above, research on HL phonology indicates that HSs tend to develop an accent that, on the one hand, clearly does not resemble the accent of late L2 learners of the same language, but, on the other hand, also appears to bear traces that distinguish it from monolinguals' accent. In particular, it has been demonstrated that experimental groups 
comprised of HSs show strong variation regarding perceived foreign accent (e.g., Kupisch, Barton, Klaschik, Lein, Stangen, \& van de Weijer, 2014; Rato, Flores, Neves, \& Oliveira, 2015; Stangen, Kupisch, Proietti Erguen, \& Zielke, 2015), acoustic measures (Chang, Yao, Haynes, \& Rhodes, 2011; Godson, 2004; Rao, 2015) or perception tests (Chang, 2016; Lukyanchenko \& Gor, 2011). This variation is the consequence of extra-linguistic factors that constrain the acquisition of phonology.

Based on these assumptions and taking into account the variables that define our experimental group, we established the five hypotheses.

i. The accent of the HS group will be rated more closely to monolingual speech and will be clearly more distinct from the L2 learners'.

If this hypothesis is confirmed, it would indicate that early exposure to the HL, along with its continuous use during childhood and adolescence, shape HSs' accent in a way that clearly differs from advanced L2 learners' accent. If confirmed, this observation would be consistent with the results of other studies that show clear phonological advantages of HSs compared to L2 learners (Au, Knightly, Jun, \& Oh, 2002; Knightly, Jun, Oh, \& Au, 2003)

ii. The ratings of the HS group's speech will show more variation than the average ratings of monolinguals' speech.

The confirmation of this hypothesis would indicate that, in fact, early and uninterrupted exposure to a language in the context of migration does not guarantee a native-like accent (see Kupisch, Barton, Klaschik, Lein, Stangen, \& van de Weijer, 2014). A strong presence of the societal language, along with other factors related to language use, may shape HSs' pronunciation with non-native traces at the segmental (Godson, 2004) and suprasegmental (Kim, 2015) levels.

iii. Delayed contact with German (i.e., later AOA), which implies a longer period of monolingual acquisition of EP in early childhood, will correlate with a stronger perceived native accent.

If this hypothesis were true, it would mean that the acquisition of two languages from birth reduces the probability of a bilingual speaker developing clear native accents in both languages, and particularly in the minority language, as has been suggested by Kupisch, Barton, Klaschik, Lein, Stangen and van de Weijer (2014), and Stangen, Kupisch, Proietti Erguen and Zielke (2015). Furthermore, confirmation of this hypothesis would show that a longer period of monolingual acquisition during early childhood has long-term effects on the development and maintenance of a native accent in adulthood, despite later input changes.

iv. Returnees with a longer LOR in Portugal after their return will be perceived more consistently as having a native accent than non-returnee HSs or returnees with a relatively short LOR in Portugal. 
If confirmed, this result would reinforce that accent is susceptible to changes over speakers' lifespans, even in adulthood, as has been suggested by, for instance, De Leeuw, Schmid and Mennen (2010), and Hopp and Schmid (2013). In this case, however, unlike the aforementioned studies, confirmation of this hypothesis would imply the loss of non-native traces in the accent of bilingual speakers whose HL was acquired as a minority language. In other words, this would demonstrate that a change from an environment where the HL is the minority language to an environment where it is the societal language leads to changes in the direction of a native-like accent.

v. Returnees who moved to Portugal in early adolescence will be perceived as sounding more native-like than returnees who remigrated as adults. Additionally, returnee HSs who lived a shorter period in the host country will also be perceived as sounding more native-like than returnee HSs with a longer LOR in the host country.

This hypothesis correlates with the previous prediction. If the phonological competence of bilingual speakers continues to be susceptible to changes after a supposed critical period for the acquisition of phonology (according to Abrahamsson \& Hyltenstam, 2009, it is around age 12), a correlation between the variables age at return and LOR in the host country and degree of perceived non-native accent would be found. If, on the other hand, accent is mainly shaped by exposure in early childhood, no effects of variables related to input changes in adolescence/adulthood would be revealed.

\section{RESULTS}

This section presents the individual and group results, which are organized by speakers' average rating points as well as by raters' mean evaluations per group. In a second step the statistical results of non-parametrical between-group comparisons and within-group correlations are shown. Figure 1 indicates the average points accumulated for each speaker in each group.

Similar to the results from Rato, Flores, Neves and Oliveira's (2015) study, there is a clear difference between both control groups (i.e., monolingual and L2), which represent the endpoints on a continuum of nativeness. In the monolingual group, the participants were consistently rated as native speakers of EP, with a mean rating of 1.11 ( $\mathrm{SD}=0.05$ ), ranging from 1.05 to 1.17 . On the contrary, the L2 learners were consistently rated as having a strong foreign accent. In this group, the mean rating was $7.24(\mathrm{SD}=0.4)$, with a range of 6.67 to 7.60 points. This mean value lays almost two points below the extreme point of the scale (i.e., 9), which can be seen as evidence of the high proficiency of the L2 learners.

Concerning the heritage bilingual group, first, as shown in several previous studies (see the discussion above), the ratings of their speech show more variation in terms of degree of nativeness of their accent, ranging from 1.33 to 3.32 (mean 1.79, SD =0.63). Second, even though many heritage bilinguals' speech has rating averages close to those of monolingual speakers, no bilingual actually falls within the monolinguals' rating span (1.05-1.17). Five speakers show mean ratings that lay above point $2(2.02-3.32)$. Third, further evidence of their variation is the fact that ratings of the heritage bilinguals' speech ratings are quite distant from evaluations of the L2 learners' speech. 
Figure 1. Individual Results Per Group (1-9 scale)

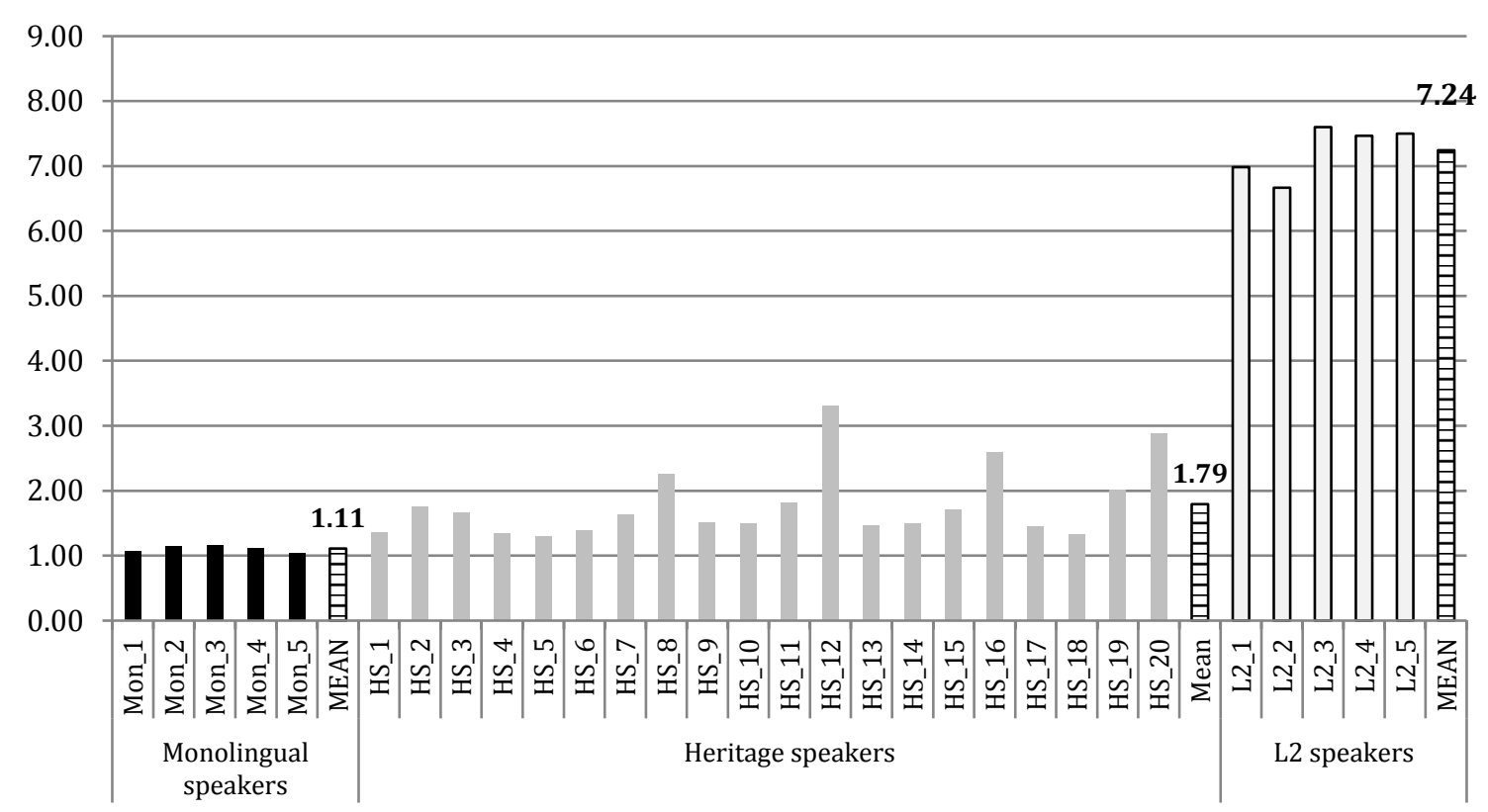

Figure 2 shows the average ratings given by each rater for each group of speakers. The results indicate that some raters were stricter than others in judging foreign accent; however, all of them made clear distinctions between the L2 learners and the monolingual and heritage bilingual speakers. Regarding the last two speaker groups, only three raters did not distinguish between monolinguals and heritage bilinguals, judging all of them as having a clear native accent. One rater (R17) evaluated the monolinguals with slightly higher average points than the bilinguals (1.5 versus 1.25$)$. All other 26 raters gave lower mean rating points to the monolinguals than to the bilinguals, meaning that they detected differences between these two speaker groups. 
Figure 2. Average Rating per Group by Rater

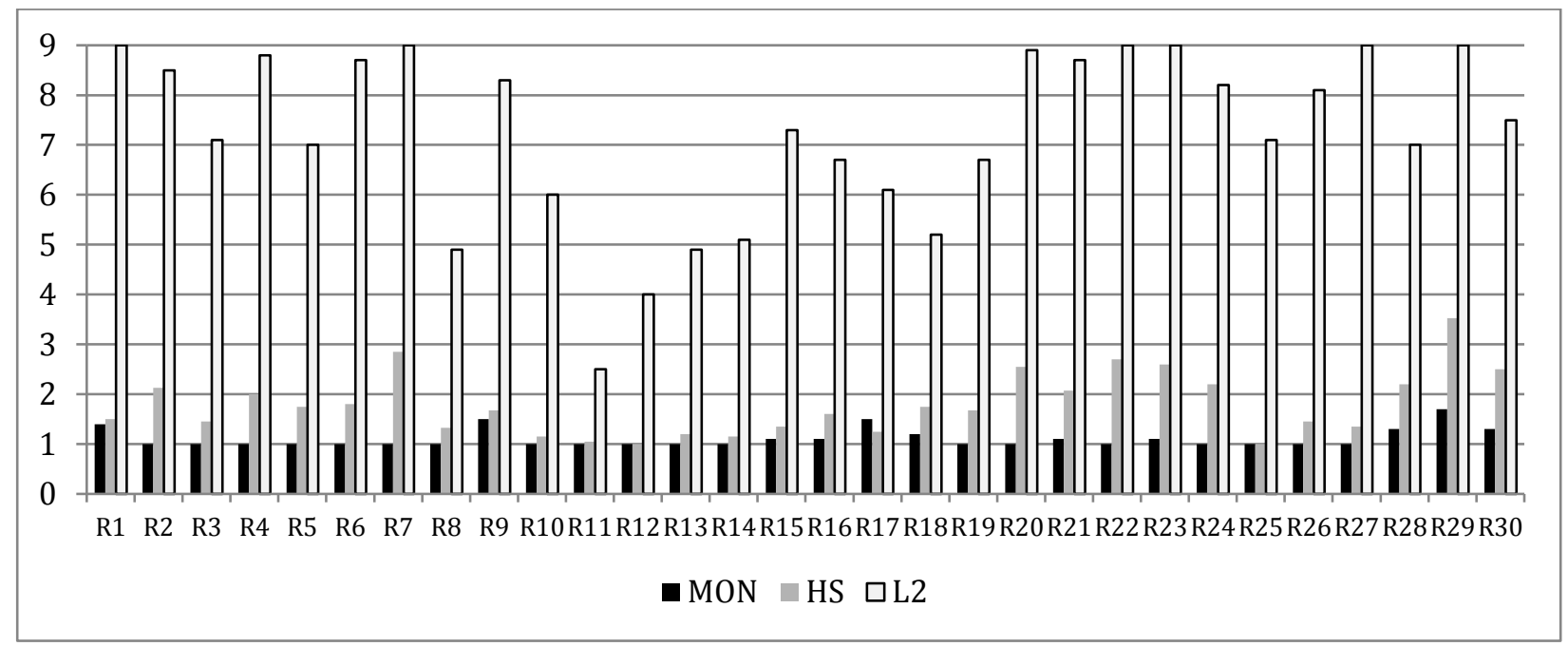

Regarding the ICC, a high degree of inter-rater reliability was found; the average interclass correlation (ICC) was .992 with a $95 \%$ confidence interval from .987 to $.996(\mathrm{~F}(29,842)=$ $126.336, p<.001)$.

The Kruskal-Wallis test for inter-group comparison corroborated that the three groups differed significantly concerning the evaluation of their accent $(H(2)=20.166, p<.001)$. Follow-up Mann-Whitney tests with Bonferroni correction (the significance level was set to 0.017) showed that all groups received significantly different accent ratings: monolinguals' ratings differed from HSs and L2 learners $(U=0.000, p=.009)$ and HSs' ratings differed from L2 learners $(U=$ $0.000, p=.001)$. There were also significant differences between ratings of the heritage and monolingual groups $(U=0.000, p=.001)$.

Concerning the correlation between age of emigration and perceived rating, the Pearson correlation test showed a negative correlation between both variables $(r=-.352)$, indicating that there is an association between delayed contact with the societal language (i.e., higher age of emigration), German, and the development of a more native-like accent in heritage EP (i.e., lower ratings). This trend is illustrated in Figure 3 . The correlation is not statistically significant ( $p=.128$ ), but a closer look at the individual results shows that four out of the five speakers with ratings above 2 were born in the host country, and thus began their contact with German earlier than those speakers who emigrated during their childhood.

Interestingly, when we excluded HS_12, who emigrated at age 3 and received the highest mean rating (3.32 points), and we performed an additional Pearson correlation test without this outlier, the results showed a significant association between a later emigration and a more native-like accent $(r=-.398, p=.037)$. 
Figure 3. HSs' Average Ratings in Correlation with Age of Emigration

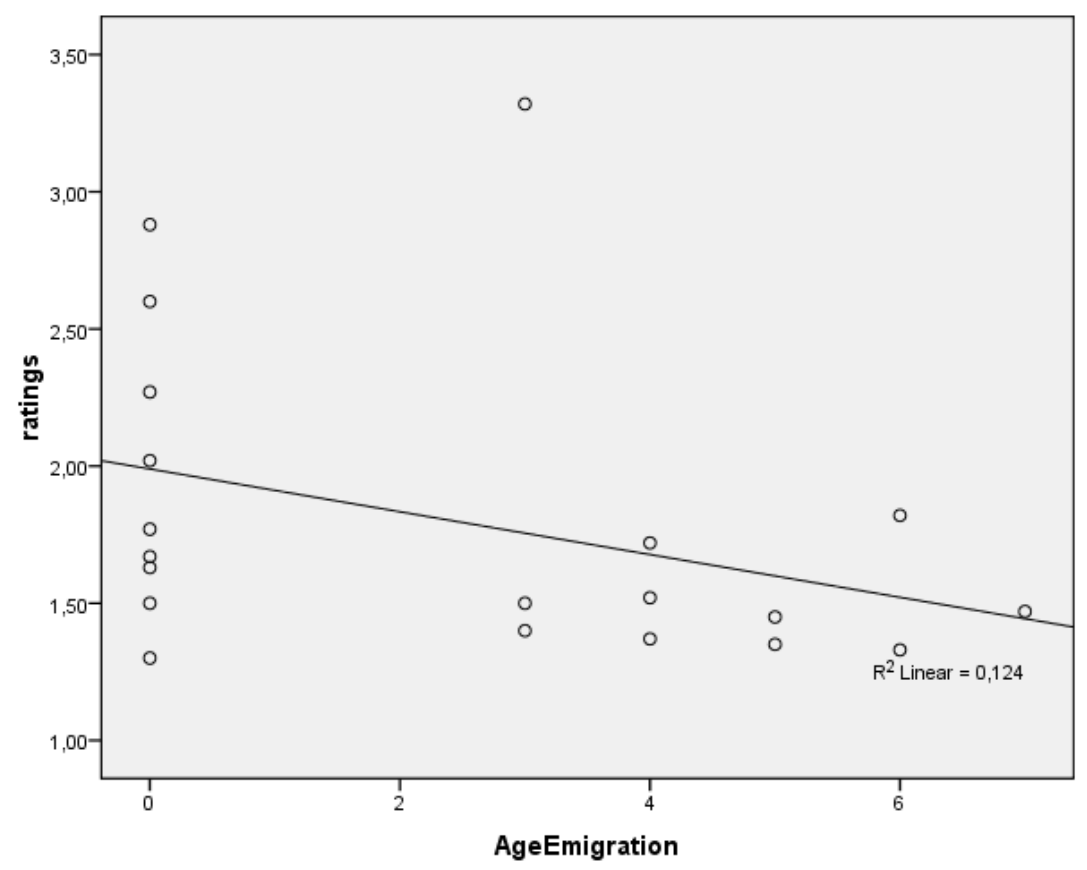

The Pearson test on the correlation between LOR in Portugal and perceived rating also showed a negative correlation between both variables $(r=-.296)$, indicating that a longer residence back in Portugal (i.e., a higher LOR) is associated with the development of a more native-like accent (i.e., a lower average rating) than a shorter stay. Even though this correlation was not statistically significant $(p=.276)$, as was the case with the previous variable, a closer look at the individual results (see Figure 4) shows that four out of the five speakers with average ratings above 2 were still living in Germany or had lived in Portugal for less than one year at the time of the experiment. 
Figure 4. HSs' Average Ratings in Correlation with LOR in Portugal

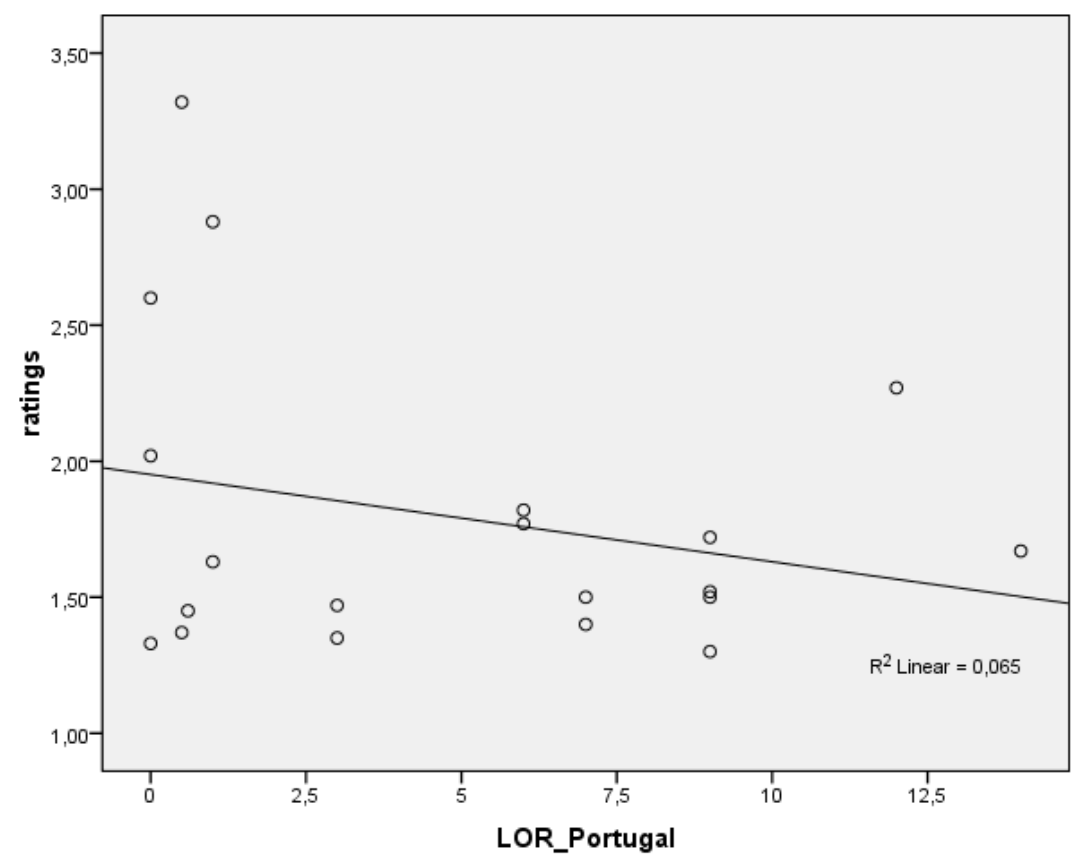

As for the correlation between LOR in the host country and perceived rating averages, again, a Pearson test showed a correlation $(r=.272)$. Unlike the previous two variables, this correlation was positive; that is, the longer the length of stay in a German-speaking environment, the higher the rating averages were (i.e., indicating a less native-like accent). However, the correlation was not statistically significant $(p=.246)$. The weak association between both variables is also shown by the dispersion displayed in Figure 5. 
Figure 5. HSs' Average Ratings in Correlation with LOR in the Host Country

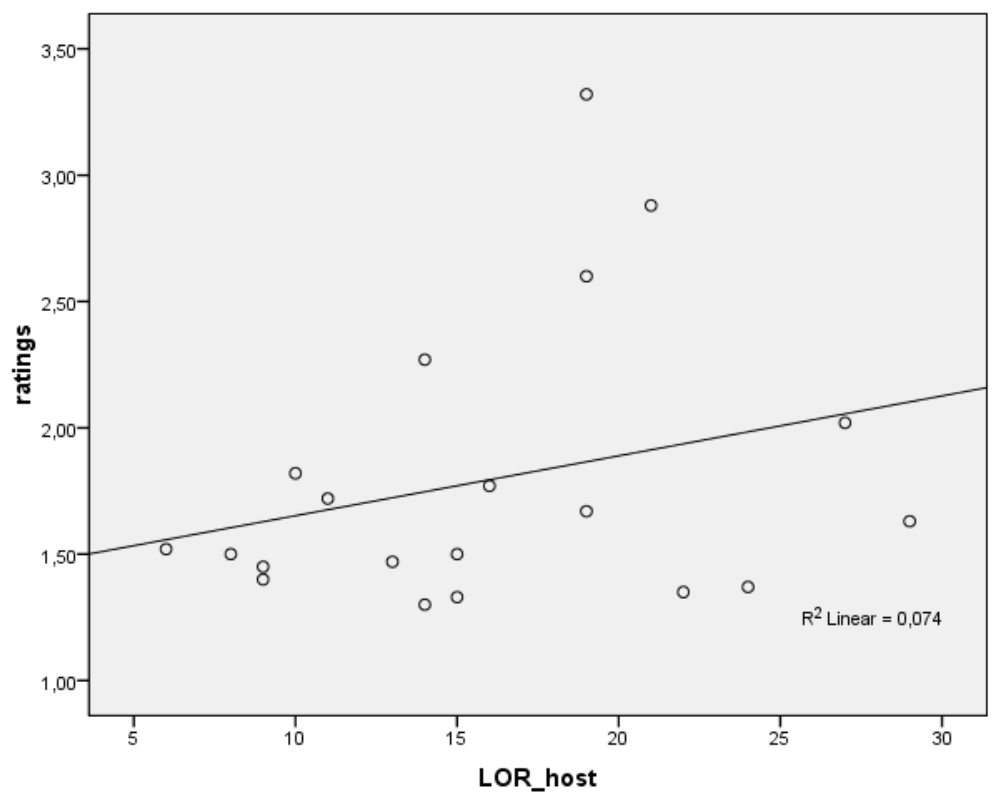

Finally, a final set of Pearson Correlation results showed that there is almost no correlation between age at return and rating average $(r=.091, p=.729)$. Thus, the age at which a HS moved to Portugal is not associated with a perceived native accent per se.

\section{DiscuSSION AND CONCLUSIONS}

The present study explored the question of whether variables related to input changes in early childhood (i.e., age at emigration), on the one hand, and in adolescence/adulthood (i.e., through returning to a homeland), on the other hand, would have an effect on the perceived accent of HSs, or bilingual speakers who grew up in a context of migration. Speech samples of 20 HSs of EP who live(d) in a German-speaking country, five monolingual speakers, and five proficient L2 learners of EP were rated by a group of 30 native EP speakers on a 9-point rating scale. The HSs differed in their age at emigration, which ranged from 0 to 7 years, and the time spent in the country of migration. Seventeen HSs no longer lived in their German-speaking host country at the time of data collection.

Overall, the results showed that the accent of HSs, independent of variables related to input changes, was perceived as being more similar to monolinguals' than to L2 learners'. Even though no HS fell within the monolinguals' rating span, which ranged from 1.05 to 1.17 , the mean rating of the HS group was still below 2. This means that, even when detecting slight nonnative traces in the HSs' accent, raters still clearly distinguished the HSs from the L2 learners, and these differences showed strong significance in our statistical outputs. At this point, it should be highlighted that only six raters placed all L2 learners in the highest level of the foreign accent scale (9-points), which corresponds to the most discernable foreign accent. Six raters judged them lower or close to 5 and the other 18 raters placed them between these points, which reflected the L2 learners' high EP language proficiency. Our results therefore, confirmed our 
first research hypothesis. In fact, early exposure to the HL shaped the HSs' accent in a way that is clearly different from the advanced L2 learners' accent. These results were consistent with the conclusions of other studies on HSs' phonological competence, which showed clear advantages in this domain when HSs were compared to L2 learners (Au, Knightly, Jun, \& Oh, 2002; Kim, 2015; Knightly, Jun, Oh, \& Au, 2003). Another factor that needs to be further addressed is exposure to Portuguese in the classroom, since it may affect HSs' accent. Although classroom exposure was not a variable analyzed in this study, the weekly two-hour formal education and socialization in Portuguese that our HSs received may have had an effect on their near nativelike speech, as previously attested by Nagy and Kochetov (2013).

Nevertheless, the statistical results also showed significant differences between ratings of the HSs' speech and those of the monolinguals' speech. In particular, the HS group presented more variation than the monolingual group. This indicates that the raters detected non-native traces in the HSs' speech. This observation is consistent with the findings reported by Kupisch, Barton, Klaschik, Lein, Stangen and van de Weijer (2014), and Stangen, Kupisch, Proietti Erguen and Zielke (2015), whose studies were also based on foreign accent ratings. Even though this methodology was reliable in analyzing our speakers' perceived accent, further analyses at the suprasegmental and the segmental levels are necessary in order to detect the features that might be responsible for the reported differences. Studies that used finer acoustic measures have shown that differences may be found in domains such as word stress (Kim, 2015), VOT (Hrycyna, Lapinskaya, Kochetov, \& Nagy, 2011; Lein, Kupisch, \& van de Weijer, 2015; Nagy \& Kochetov, 2013), intervocalic consonant realization (Rao, 2015) or vowel production (Godson, 2004; Ronquest, 2013).

The variation found within the HS group, and the fact that the majority of the listeners rated the heritage bilinguals at a higher level than the monolinguals (see Figure 2), confirmed our second hypothesis. Even though early and uninterrupted exposure to a language in the context of migration fosters a more native-like accent, it does not guarantee the development of two independent monolingual-like phonological systems in the bilingual speaker. The strong presence of the societal language, along with other factors related to language use, seem to shape HSs' accent with non-native traces, which need to be identified for heritage Portuguese in future work.

Finally, we investigated the role of variables related to input changes. The HS group comprised speakers who were born in a German-speaking country $(n=9)$, who emigrated at age three or four $(n=6)$ and between the ages of five and seven $(n=5)$. Additionally, 17 speakers out of the 20 HS participants no longer lived in Germany/Switzerland, but rather had returned to Portugal between the ages of 11 and 29. The group of returnees included speakers who were living in Portugal for one year or less $(n=5)$, for three years $(n=2)$, for six to seven years $(n=4)$, for nine years $(\mathrm{n}=4)$ or for 12 to 14 years $(\mathrm{n}=2)$. This breakdown points to a LOR in the host country of 6 to 29 years (mean $=16$ years). Due to the high variation within the group, we decided to analyze the results based on correlations and not divide the group into further subgroups. 
Pearson correlations showed that globally, there was an association between the extra-linguistic variables examined and the degree of perceived native accent of the HS group. However, correlations were not strong and statistically not significant. Only the variable age of emigration showed a significant correlation with degree of perceived nativeness, and this arose only after one outlier was excluded from the analysis. In particular, the results without the outlier suggest that delayed contact with the societal language (i.e., a longer period of monolingual acquisition in the early years) fosters the development of a native accent. Individual results confirmed this association, since four out of the five speakers with ratings above 2 were born in the host country. These results imply that the probability of developing accented speech in the minority language increases if speakers have contact with the societal language right from birth, which is in line with the conclusions from other studies on HL phonology (Godson, 2004; Kupisch, Barton, Klaschik, Lein, Stangen, \& van de Weijer, 2014; Lein, Kupisch, \& van de Weijer, 2015; Stangen, Kupisch, Proietti Erguen, \& Zielke, 2015). In sum, we have provided further support for the notion that early contact with the majority language leads to transfer from the societal language in certain segmental or suprasegmental domains.

Our results further suggest that, once shaped in early childhood, HSs' accent does not change easily; that is, a prolonged duration back in Portugal did not guarantee a higher degree of perceived nativeness. The individual results support this conclusion: the two speakers with the longest LOR in Portugal (HS_8 = 12 years, HS_3 = 14 years) were not the speakers who received more native-like ratings $\left(\mathrm{HS} \_8=2.27\right.$, HS_3 $\left.=1.77\right)$. HS_1, for instance, who had lived in Portugal for five months at the time of data collection, was rated more closely to the monolinguals $\left(\mathrm{HS} \_1=1.3\right)$ than the previous two speakers. Interestingly, HS_8 and HS_3 were both born in Germany, while HS_1 emigrated at the age of four, thus initiating contact with the societal language at a later stage of development.

The facts that the raters and the monolingual speakers were recruited in a single region (i.e., northwest Portugal), and that the parents of the HSs were from the same region, suggest that regional accent did not play a role in global accent ratings. However, further investigation of phonological changes that may have occurred in recent decades in the region in question is called for, since these changes could be another factor accounting for differences between the accents of monolinguals and HSs.

The absence of a strong, significant correlation between a longer LOR in Portugal and the presence of a significant correlation with age of emigration (after excluding the outlier) suggests that accent is predominantly shaped in the early years of development. Input changes in adulthood may affect speakers' L1 accent in cases of a very long stay in an L2 environment, along with strongly reduced language use, as has been shown, for instance, by De Leeuw, Schmid and Mennen (2010). However, in the case of heritage returnees, who moved to their HL environment in adolescence/adulthood, after spending their childhood in an L2 environment, this change did not appear to influence their pronunciation. This suggests that acquired non-native traces may last in returnees' speech over a lifetime and may never be modified to reflect monolingual speech. To prove this assumption, however, returnees with an even longer LOR in their homeland need to be investigated. Finally, the present discussion is also tied to the lack of strong correlations between perceived nativeness and age at return or LOR in the host country. 
In turn, the tendency to maintain the accent that was shaped in early development might also be observed in the societal language, which, in the case of the returnees, becomes the minority language in the country of origin. Kupisch, Lein, Barton, Schröder, Stangen and Stoehr (2014) showed that a native-like accent in the societal language of one's childhood environment can be maintained even after long-term residence in the HL country. Examining changes to the returnees' German accent after returning to Portugal would be, thus, a promising area of future inquiry. Furthermore, foreign accent rating is a subjective assessment method because it is based on listeners' individual perception of nativeness; therefore, in the future, studies similar to the current one should be complemented by more objective analyses that measure acoustic data.

\section{ACKNOWLEDGEMENTS}

This work was supported in part by the following FCT-Grants: EXPL/MHC-LIN/0763/2013 (Portuguese as Heritage Language and Language Change), POCI/LIN/59780/2004 (PortugueseGerman bilingualism in the European context) and PTDC/CLE-LIN/112939/2009 (Sociolinguistic Profile of Braga speech).

\section{REFERENCES}

Abrahamsson, N., \& Hyltenstam, K. (2009). Age of onset and nativelikeness in a second language: Listener perception versus linguistic scrutiny. Language Learning, 59(2), 249-306.

Au, T. K., Knightly, L. M., Jun, S.-A., \& Oh, J. S. (2002). Overhearing a language during childhood. Psychological Science, 13, 238-243.

Benmamoun, E., Montrul, S., \& Polinsky, M. (2013). Heritage languages and their speakers: Opportunities and challenges for linguistics. Theoretical Linguistics, 39(3/4), 129-181.

Campbell, R., \& Rosenthal, J. (2000). Heritage languages. In J. W. Rosenthal (Ed.), Handbook of undergraduate second language education (pp. 165-84). Mahwah, NJ: Lawrence Erlbaum.

Chang, C. B. (2016). Bilingual perceptual benefits of experience with a heritage language. Bilingualism. Language and Cognition, 19(4), 791-809.

Chang, C. B., Yao, Y., Haynes, E. F., \& Rhodes, R. (2011). Production of phonetic and phonological contrast by heritage speakers of Mandarin. Journal of the Acoustical Society of America, 129, 3964-3980.

De Leeuw, E., Schmid, M., \& Mennen, I. (2010). Perception of foreign accent in native speech. Bilingualism: Language and Cognition, 13(1), 33-40.

Flege, J. E., Munro, M. J., \& MacKay, I. R. A. (1995). Factors affecting strength of perceived foreign accent in a second language. Journal of the Acoustical Society of America, 97, 31253134.

Flege, J. E., Frieda, E. M., \& Nozawa, T. (1997). Amount of native-language (L1) use affects the pronunciation of an L2. Journal of Phonetics, 25, 169-186.

Flege, J., Yeni-Komshian, G., \& Liu, S. (1999). Age constraints on second language learning. Journal of Memory and Language, 41, 78-104.

Flores, C. (2015). Understanding heritage language acquisition: Some contributions from the research on heritage speakers of European Portuguese. Lingua, 164, 251-265.

Flores, C., \& Rauber, A. (2011). Perception of German vowels by bilingual Portuguese-German returnees: A case of phonological attrition? In E. Rinke, \& T. Kupisch (Eds.), The 
development of grammar: Language acquisition and diachronic change - Volume in honor of Jürgen M. Meisel (pp. 287-305). Amsterdam, Netherlands: John Benjamins.

Godson, L. (2004). Vowel production in the speech of Western Armenian heritage speakers. Heritage Language Journal, 2(1), 44-69.

Hopp, H., \& Schmid, M. (2013). Perceived foreign accent in L1 attrition and L2 acquisition: the impact of age of acquisition and bilingualism. Applied Psycholinguistics, 34(2), 361-394.

Hrycyna, M., Lapinskaya, N., Kochetov, A., \& Nagy, N. (2011). VOT drift in 3 generations of heritage language speakers in Toronto. Canadian Acoustics, 39(3), 166-167.

Kim, J.-Y. (2012). Discrepancy between the perception and production of stop consonants by Spanish heritage speakers in the United States (Master's thesis). Korea University, Seoul. Retrieved from

http://dcollection.korea.ac.kr/jsp/common/DcLoOrgPer.jsp?sItemId=000000034097

Kim, J.-Y. (2015). Perception and production of Spanish lexical stress by Spanish heritage speakers and English L2 learners of Spanish. In E.W. Willis, P.M. Butragueño, \& E. H. Zendejas (Eds.), Selected proceedings of the 6th Conference on Laboratory Approaches to Romance phonology (pp. 106-128). Somerville, MA: Cascadilla Proceedings Project.

Knightly, L. M., Jun, S.-A., Oh, J. S., \& Au, T. (2003). Production benefits of childhood overhearing. Journal of Acoustical Society of America, 114(1), 465-374.

Kupisch, T., Barton, D., Klaschik, E., Lein, T, Stangen, I., \& van de Weijer, J. (2014). Foreign accent in adult simultaneous bilinguals. Heritage Language Journal, 11(2), 123-150.

Kupisch, T., Lein, T., Barton, D., Schröder, D. J. Stangen, I., \& Stoehr, A. (2014). Acquisition outcomes across domains in adult simultaneous bilinguals with French as weaker and stronger language. Journal of French Language Studies, 24(3), 347-376.

Lein, T., Kupisch, T., \& van de Weijer, J. (2015). VOT and global foreign accent in GermanFrench simultaneous bilinguals during adulthood. International Journal of Bilingualism. Online Article. doi:10.1177/1367006915589424

Lukyanchenko, A., \& Gor, K. (2011). Perceptual correlates of phonological representations in heritage speakers and L2 learners. Proceedings of the 35th Annual Boston University Conference on Language Development (pp. 414-426). Somerville, MA: Cascadilla Press.

Montrul, S. (2008). Incomplete acquisition in bilingualism: Re-examining the age factor. Amsterdam, Netherlands: John Benjamins.

Montrul, S. (2010). Current issues in heritage language acquisition. Annual Review of Applied Linguistics, 30, 3-23.

Montrul, S. (2015). The acquisition of heritage languages. Cambridge, England: Cambridge University Press.

Munro, M. J., \& Derwing, T. M. (1994). Evaluations of foreign accent in extemporaneous and read material. Language Testing, 11(3), 253-266.

Nagy, N., \& Kochetov, A. (2013). VOT across the generations: A cross-linguistic study of contact-induced change. In P. Siemund, I. Gogolin, M. Schulz, \& J. Davydova (Eds.), Multilingualism and language contact in urban areas: Acquisition - development teaching - communication (pp. 19-38). Amsterdam, Netherlands: John Benjamins.

Oh, J., Jun, S.-A., Knightly, L., \& Au, T. (2003). Holding on to childhood language memory. Cognition, 86, B53-B64.

Piske, T., MacKay, I. R. A., \& Flege, J. E. (2001). Factors affecting degree of foreign accent in an L2: A review. Journal of Phonetics, 29(2), 191-215. 
Rao, R. (2015). Manifestations of /bdg/ in heritage speakers of Spanish. Heritage Language Journal, 12(1), 48-74.

Rao, R., \& Ronquest, R. (2015). The Heritage Spanish phonetic/phonological system: Looking back and moving forward. Studies in Hispanic and Lusophone Linguistics, 8(2), 403-414.

Rato, A., Flores, C., Neves, D., \& Oliveira, D. (2015). A competência fonológica de falantes bilingues luso-alemães: um estudo sobre sotaque global, compreensibilidade e inteligibilidade da sua língua de herança. Diacrítica, 29(1), 297-326.

Rauber, A., Rato, A., Kluge, D., \& Santos, G. (2012). TP (Version 3.1). [Software]. Pelotas, Brazil: Worken. http://www.worken.com.br/tp_regfree.php?1=i

Rinke, E., \& Flores, F. (2014). Heritage Portuguese bilinguals' morphosyntactic knowledge of clitics. Bilingualism: Language and cognition, 17(4), 681-699.

Ronquest, R. E. (2013). An acoustic examination of unstressed vowel reduction in heritage Spanish. In C. Howe, S. E. Blackwell, \& M. Quesada (Eds.), Selected proceedings of the 15th Hispanic Linguistics Symposium (pp. 157-171). Somerville, Massachusetts: Cascadilla Press.

Rothman, J. (2009). Understanding the nature of early bilingualism: Romance languages as heritage languages. International Journal of Bilingualism, 13(2), 155-163.

Silva-Corvalán, C. (1994). Language contact and change: Spanish in Los Angeles. Oxford, England: Oxford University Press.

Stangen, I., Kupisch, T., Proietti Erguen, A. L., \& Zielke, M. (2015). Foreign accent in heritage speakers of Turkish in Germany. In H. Peukert (Ed.), Transfer effects in multilingual language development (pp. 87-108). Amsterdam, Netherlands: John Benjamins.

Thompson, I. (1991). Foreign accents revisited: the English pronunciation of Russian immigrants. Language Learning, 41, 177-204.

Vago, R. (1991). Paradigmatic regularity in first language attrition. In H. W. Seliger, \& R. M. Vago (Eds.), First language attrition (pp. 241-252). Cambridge, England: Cambridge University Press.

Yeni-Komshian, G. H., Flege, J. E., \& Liu, S. (2000). Pronunciation proficiency in the first and second languages of Korean-English bilinguals. Bilingualism. Language and Cognition, 3(2), 131-149. 


\section{NoTE}

1. In one case the father is from Spain, but Spanish was not spoken within the family. 